\title{
Observations of Luni-Solar Precession
}

D. D. McCarthy and B. J. Luzum

U.S. Naval Observatory

Washington, DC 20992 U.S.A.

The observations of $\mathrm{d} \psi$ and $\mathrm{d} \epsilon$ used in this analysis were taken from the combination solution of the IERS Sub-Bureau for Rapid Service and Precition (McCarthy and Luzum 1991a). Besides correc. tions to the coefficients determined from VLBI, additional estimates can be derived from lunar laser ranging (LLR) observations (Williams et al. 1991; Whipple 1993). Table ?? shows a comparison of the estimates of the change in longitude and obliquity derived in this analysis with corresponding terms from analyses by other authors using different observations. The theoretical value of obliquity by Williams (1994) is also included for comparison. There are significant unexplained discrepancies among the rate estimates. Difference in the methods of the analyses such as the procesure for the estimation of the nutation coefficients and correlations within the solutions probably account for the greater part of these discrepancies. In considering the adoption of changes in the IAU model for nutation, it is important to recall that changes must also be made in the precession constant. Introduction of changes in nutation without corresponding changes in precession will not improve the agreement between observations and theory.

TABLE I

Comparison of Rates of Change in Celestial Pole Offsets

\begin{tabular}{llll}
\hline Reference & $\mathrm{d} \psi$ (mas/cy) & $\mathrm{d} \epsilon$ (mas/cy) & Note \\
\hline Charlot et al. (1991) & $-283 \pm 15$ & & \\
Williams et al. (1991) & $-270 \pm 40$ & & \\
Whipple (1993) & $-216 \pm 10$ & & \\
Williams et al. $(1993)$ & $-330 \pm 40$ & & \\
Steppe et al. $(1993)$ & $-321 \pm 60$ & $-28 \pm 5$ & \\
Walter and Ma (1993) & $-359 \pm 1$ & & \\
Walter and Ma (1993) & $-384 \pm 1$ & & Theoretical \\
Souchay et al. (1994) & $-321 \pm 3$ & $-26 \pm 1$ & \\
Herring (1994) & -299 & -24 & \\
Williams (1994) & & -24 & \\
This paper & $-309 \pm 5$ & $-16 \pm 3$ & \\
\hline
\end{tabular}

\section{References}

Charlot, P., Sovers, O.J., Williams, J.G., Newhall, X X, 1991, in Proc. IAU Coll. 127, 228.

Herring, T.A., 1994 private communication.

McCarthy, D.D. and Luzum, B.J., 1991a, Bull. Geod., 65, 22.

McCarthy, D.D. and Luzum, B.J., 1991b, A. J., 102, 1889.

Souchay, J., Feissel, M., Bizouard, N., Capitaine, N., Bougeard, M., 1994, submitted to $A \mathscr{B} A$.

Steppe, J.A., Oliveau, S.H., and Sovers, O.J., 1994, NEOS Annual Report for 1993, 28.

Walter, H.G. and Ma, C., 1994, $A \& A, 284,1000$.

Whipple, A., 1993, private communication.

Williams, J.G., Newhall, X X, and Dickey, J.O., 1991, A\&A, 241, L9

Williams, J.G., Newhall, X X, and Dickey, J.O., 1993, in Contributions of Space Geodesy to Geodynamics: Earth Dynam. ics, Geophs. Monog. AGU, 24, D.E. Smith and D.L.Turcotte (eds), 83.

Williams, J.G., 1994, A. J., 108, 711. 